\title{
Abundance and activity pattern of avifauna in ashewa local vulture restaurant, dire dawa, eastern Ethiopia
}

\begin{abstract}
The study was aimed to conduct avifaunal abundance and their activity pattern in Ashewa local vulture restaurant, eastern Ethiopia during March-May 2014. A preliminary survey was undertaken to categorize the study site based on habitat types of the area. The sampling segments were designed based on stratification of the habitat in to three categories. Ten point count stations of 50meter apart were established in sandy site, wet waste drainage and dry bare lands. Accordingly, line transect method was delineated with white paint and installed wooden materials at the margin of the stratified habitats. Subsequently, point count method was used to count the abundance of dumping site visiting avifauna. Threats facing by the birds in the study area were also recorded. A total of 1,088 individual birds of six species belonging to three families were recorded. The most abundant species was Hooded Vulture (Necrosyrtes monachus) $(41.05 \%)$ followed by Tawny Eagle (Aquila rapax) $(34.65 \%)$ and Little Egret $(20.7 \%)$. The present study revealed that, the presence of dumped food increased the abundance and activity pattern of birds in the projected site. Availability of various artificial and natural perch sites in the study area as favorable for different birds of conservation importance. Various factors like waste collectors, free ranging domestic dogs and cats to affect the activity pattern of birds.
\end{abstract}

Keywords: avifauna, vulture restaurant, abundance, management plan, activity pattern, threats
Volume I Issue I - 2016

\author{
Getachew Mulualem,' Shimles Ayalew, ${ }^{2}$ \\ Weldemariam Tesfahunage' \\ 'Ethiopian Biodiversity Institute, Wildlife Studies, Ethiopia \\ ${ }^{2}$ Department of Biology, Dire Dawa University, Ethiopia
}

Correspondence: Getachew Mulualem, Ethiopian Biodiversity Institute,Wildlife Studies, Mekelle, P.O. Box: 30726, Tigray, Ethiopia, Email gechozol@gmail.com

Received: June 21, 2016 | Published: July 20, 2016

\section{Introduction}

The diversity of Ethiopian fauna is high owing to diverse climate, vegetation and terrain. ${ }^{1}$ Subsequently, it has diverse topography, ranging from the Denakel depression, approximately $100 \mathrm{~m}$ below sea level in the north-east, through the Great African Rift Valley dissecting the country from north-east to the south, to the Afro-Alpine Ecosystems ( $>3700 \mathrm{~m}$ above sea level) in the north-western, central and southern highlands. ${ }^{2,3}$ Several authors already cited the variations in topography of the countries as one of the reasons for high faunal and floral diversity and the extent of endemism. ${ }^{4,5}$ Ethiopia has one of the richest bird resources in the African continent encompassing 69 Important Bird Areas (IBAs), ${ }^{6}$ and over 900 bird species including 21 endemics. $^{7}$ As well, the country hosts numerous stop over sites for millions of migratory birds crossing the Sahara Desert. ${ }^{8}$

Avian diversity is often used as one of the most important indicators of habitat quality. ${ }^{8,9}$ Several literatures shown that, avian diversity has declined in Africa in recent decades, mainly through loss and fragmentation of foraging habitats and nesting sites due to deforestation for new settlements, agricultural expansion and logging. ${ }^{10,11}$ Moreover, most avian conservation efforts in Africa are mainly concentrated in protected areas. ${ }^{12,13}$ Several programs are in effect to help conservation and management of wildlife in Ethiopia. The Ethiopian Wildlife and Natural History Society was started during 1966 which focus on studying and promoting the natural environments of Ethiopia along with spreading the knowledge they acquired and supporting legislation to protect environmental resources. ${ }^{14}$

Birds have proved to be excellent indicator of biodiversity and vital for ecological functioning of environment such as indicator of pollution, seed dispersal, scavenging offal and predators of numerous insects and other pests. ${ }^{15}$ The presence of diverse bird population capable of sustained reproduction is one of the indications of healthy environment. ${ }^{16}$ Birds are often used as biological model because they are good ecological indicators and they are easily observable. ${ }^{17}$ To understand how different physical factors influence the distribution and abundance of avian species, we usually use to measure change in abundance and activity pattern over time. Population status and species composition of birds of prey around waste disposal locations are globally declining owing the advanced waste management systems. Ashewa local vulture restaurant is a home for various globally important vultures' species. The presence of regular waste disposal nearby the area makes the abundance of avifauna diverse. In addition to this, human and other domestic animals within their food source are disturbing their feeding and roosting habits. Abundance and activity pattern of birds around waste disposal site in Dire Dawa city is poorly known. Hence, the present study deals the abundance and activity pattern of birds in Ashewa local vulture restaurant, eastern Ethiopia.

\section{Materials and methods \\ Description of the study area}

This study was conducted in Ashewa damping area (kebele 09) in Dire Dawa city $\left(9^{\circ} 35^{\prime} \mathrm{N}\right.$ and $\left.41^{\circ} 52^{\prime} \mathrm{E}\right)$ Administrative eastern part of Ethiopia. Annual average temperature is $25.3^{\circ} \mathrm{C}$, and rain fall is $657 \mathrm{~mm}$. Also the study area contained some vegetation like deciduous plants (Acacia trees species). Total area of the study site is around $250 \mathrm{~m}^{2}$ (approximately) covered by border of building and dampso as to control flood and also serve as highway. The study site were the waste are disposed is predominantly sandy soil cover. During rainy period the amount (quantity) of waste disposal that are variable to bird species is decreased due to removing by flood ${ }^{18}$ (Figure 1). 


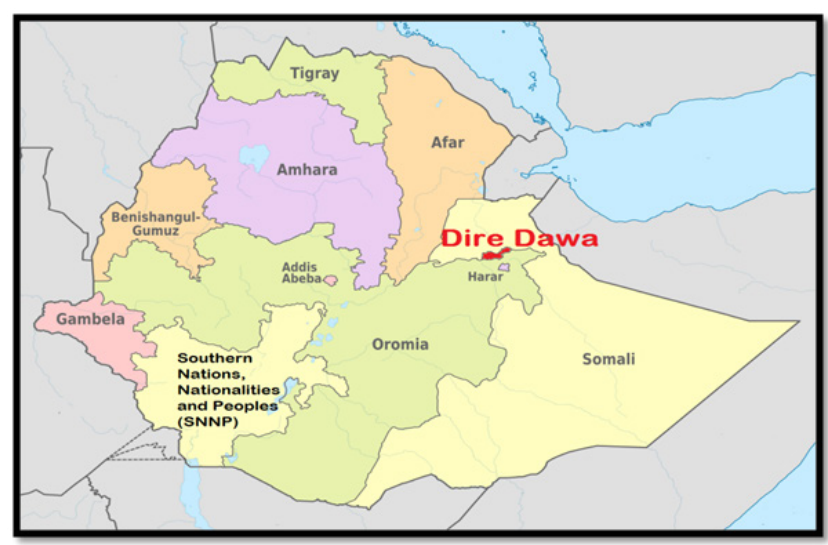

Figure I Map of the study area (Dire Dawa cityAdministration, Eastern Ethiopia).

\section{Methods}

Preliminary survey was conducted in an effort of observing the overall landscape to stratify the habitat for line transects segments and setting point count stations. Avifaunal survey was carried out using distance sampling point count methods from March to May 2014. The sampling segments were designed based on stratification of the habitat in to three categories. Accordingly, line transect method was delineated with white paint and installed wooden materials at the margin of the stratified habitats. Ten point count stations 50meter apart were established in sandy site, wet waste drainage and dry bare land. The count was made for a period of 15 minutes within the counting station. Stations were surveyed for birds every two weeks twice a day (in the early morning $0700-1000 \mathrm{hr}$ and $1600-1800 \mathrm{hr}$ in the late afternoon)) in following Aynalem \& Bekele. ${ }^{19}$ Birds were physically observed using binocular (7x35) and identified using naked eye within a short distance and easily categorized by their physical appearance. Our identification was also further confirmed through standard bird field guides. Avian threat factors that threaten the survival of birds of prey and activity pattern were recorded through observation checklist. Double counting of birds within the line transect was ignored.

\section{Results}

\section{Species composition of birds}

In the present study a total of 1,088 individual birds of six species belonging to three families were recorded (Table 1). Families with the highest number of species were Corvidae followed by Accipitridae and Ardeidae (Table 2). Of the total species recorded one species Thick-billed Raven (Corvus crassirostris) is endemic to the Ethiopia, and one species is Critically Endangered. ${ }^{20}$

Table I List of birds recorded at Ashewa local vulture restaurant

\begin{tabular}{lllll}
\hline Order & Family & Common name & Scientific name & IUCN status \\
\hline Accipitriformes & Accipitridae & Hooded Vulture & Necrosyrtes monachus & Critically Endangered \\
Accipitriformes & Accipitridae & Tawny Eagle & Aquila rapax & Least Concern \\
Passeriformes & Corvidae & Pied Crow & Corvus albus & Least Concern \\
Passeriformes & Corvidae & Somali Crow & Corvus edithae & Least Concern \\
Passeriformes & Corvidae & Thick-billed Raven & Corvus crassirostris & Least Concern \\
Pelicaniformes & Ardeidae & Little Egret & Egretta garzetta & Least Concern \\
\hline
\end{tabular}

Table 2 Relative abundance of birds in Ashewa local vulture restaurant

\begin{tabular}{lll}
\hline Species & No of individuals & Abundance (\%) \\
\hline Hooded Vulture & 447 & 41.05 \\
Tawny Eagle & 377 & 34.65 \\
Pied Crow & 10 & 0.9 \\
Somali Crow & 17 & 1.6 \\
Thick-billed Raven & 12 & 1.1 \\
Little Egret & 225 & 20.7 \\
& 1088 & 100 \\
\hline
\end{tabular}

\section{Activity pattern of birds}

Avian activities were recorded throughout the study period and classified as soaring, feeding, appeasement displays, watching alert posture, flying, roosting, body care and basking.

The commonly observed activity of birds was their feeding habit; usually the Hooded Vultures and Tawny Eagles started feeding in the damping site from $1130 \mathrm{hr}$ to $1330 \mathrm{hr}$.

After reaching the dumping site they were perched on the nearby structures rather than involving in feeding directly. The Little Egrets were observed to feed apart from the vultures and feeding differently in moistened wastes. Thick-billed Ravens were usually feeding after Hooded Vultures and in time when the Tawny Eagles left the area. Thick-billed Ravens were also feeding the scrap of meat that left from other vultures and eagles. After feeding the Hooded Vultures and Tawny Eagles raise their feather, shake their bodies and stretch their wings before settling feather back into place. Conflict at the feeding site was frequently occurred among vultures in area where flesh scraps and different waste disposal were disposed. After feeding they return to their perching trees and buildings walls. The activity of bird species was varying during dry and rainy period, during dry period there was diversely active and possess crowding during feeding activity while, during rainy period their activity of feeing was less diverse and freely active (Figure 2).

There was no variation in the number of bird species observed in the morning and afternoon during the dry season except in Hooded Vultures and Tawny Eagles (Figure 3). The Hooded Vultures and Tawny Eagles were more abundant during afternoon than in the morning. As well, they are observed on the wall of the buildings in both morning and afternoon times.

There was also no more variation in the number of individual birds during morning and afternoon in wet period except Hooded Vultures, Tawny Eagles and Little Egret (Figure 4). The Hooded Vultures, 
Tawny Eagles and Little Egrets were more abundant in the morning than in afternoon.
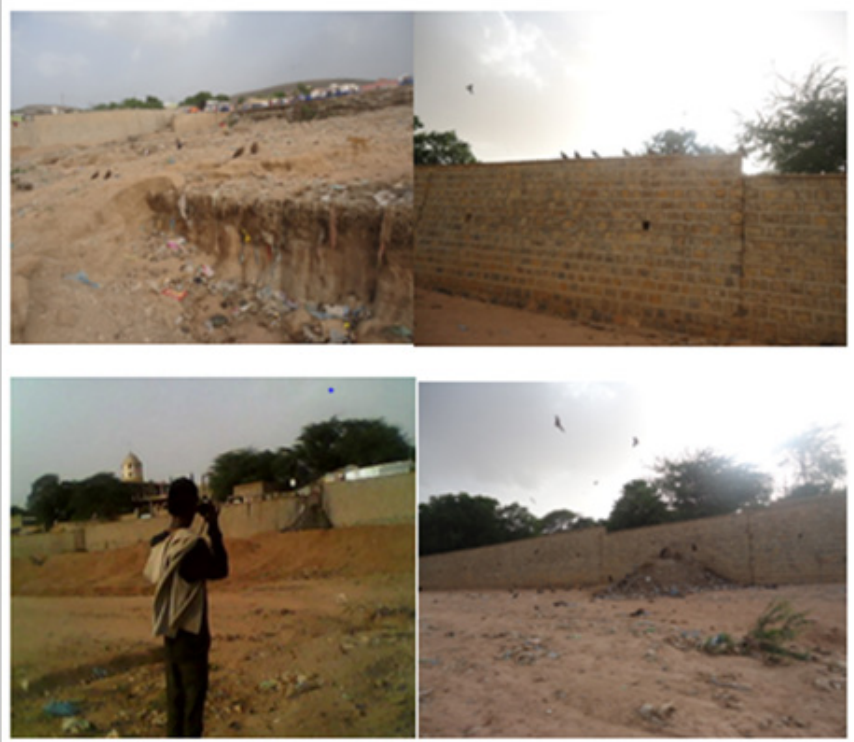

Figure 2 Activity pattern of birds in Ashewa dumping site (Photos: Medina Ahmed, 2014).

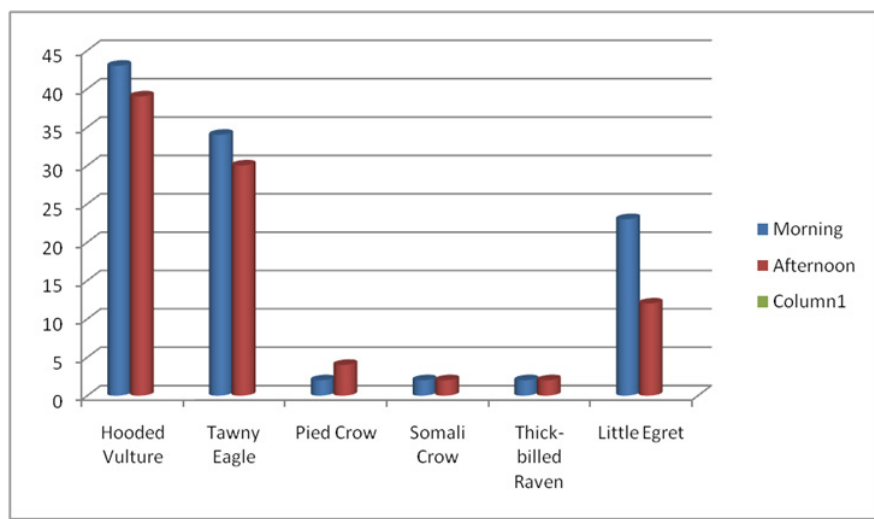

Figure 3 Number of birds recorded in both morning and afternoon of dry season.

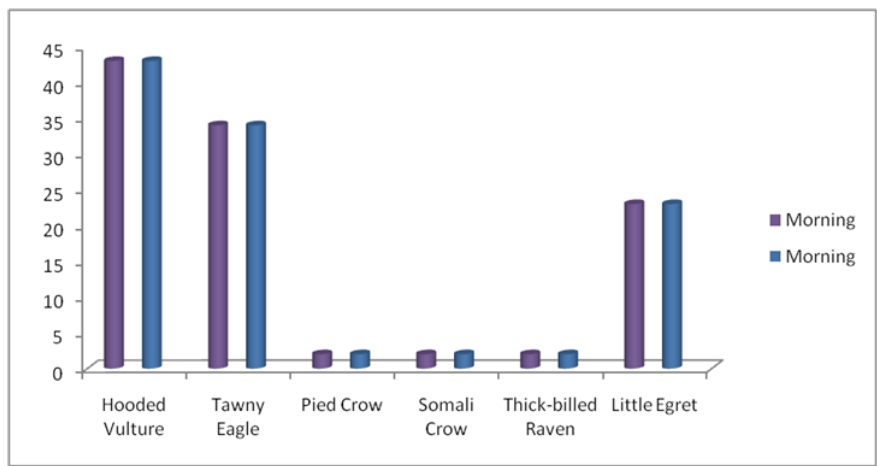

Figure 4 Number of birds recorded in both morning and afternoon of wet season.

\section{Feeding habit of birds}

The local vulture restaurant of birds of prey was intensively disturbed by human activities and other free ranging movement of domestic animals. Whenever there is human activities within the waste disposal site, birds perched adjacent to their feeding sites. However, when humans leave from the area, first Hooded Vultures and Tawny Eagles were landed in the sites. Hooded Vultures and Tawny Eagles start feeding in damping site during $1130 \mathrm{hr}$ to $1330 \mathrm{hr}$. Little Egrets were feeding apart from the vultures and observed feeding differently from other larger birds of prey around wet wastes. During feeding they make a squealing, hissing noise when fighting over the local vulture restaurant defined catchment.

\section{Threatening factors of birds in the local vulture restaurant}

Based on our study, waste collectors, free ranging domestic dogs and cats were key threatening factors disturbing and competing with regular activity pattern of bird species in the dumping site. Such kinds of activities were greatly affecting the abundance and activity pattern of birds in the locality.

\section{Discussion}

\section{Bird species composition}

The dumping site was used by different group of birds such as Accipitriformes, Passeriformes and Ciconiiformes. However, in wet period show a variation by increasing their number in damping site. This could be associated with less human interference as a result of flowing water in the dumping site. For example, the number of Hooded Vultures and Tawny Eagles were decreased during wet period in the vulture restaurant. The species composition of birds counted during wet and dry period was varying in number. The distribution and abundance of many bird species are determined by the composition of vegetations that forms a major element of their habitats. ${ }^{21}$ Species richness diversity during wet period, the site was contained numerous birds compared to the other near sites. These can be linked with the availability of multiple and variety of alternative food source of birds.

\section{Activity pattern of birds}

Of six bird species recorded in the survey Hooded Vultures and tawny eagles were abundant in the study site. This can be related to their strong feed preference and dependence on offal and food scraps of the locally dumped food materials. The activity pattern of birds of prey in the study area were flying, souring, perching, roosting and basking. As well, after feeding hooded vultures and tawny eagles raise their feather, shake their bodies and stretch their wings before settling feather back into place and flying to their roosting structure and basking their body during sunny time.

\section{Feeding habit of birds}

The availability of food was responsible for high population of birds in the local vulture restaurant. The major food source for birds of prey was scarp of meat and worms underneath the wet dumped materials. The finding of the current study is consistent with what has been done else were depicting the difference in feeding habit could increase the diversity, evenness and richness of birds. ${ }^{22}$ The hooded vulture and tawny eagles were arrived at early morning and late afternoon. After arrived the waste disposal site the hooded vultures are dominant by tearing flesh of food due to the presence of strong and powerful beak which end is turn dawn to tear the flesh. Vultures were social in their feeding habits as described by Weidensau. ${ }^{23}$ Ravens, little egret, pied crow and Somali crow were feed far apart from vultures and tawny eagles. 


\section{Threatening factors}

The feeding site is open dumping area with highest contact of domestic dog, cats and other animals. As well, humans are the threatening factor which disturbances the normal activity of birds in the dumping site. This phenomenon could greatly affect the abundance and activity pattern of birds. In the study area domestic dogs and waste collector was observed to chase feeding birds for their individual interest. This can have a declining effect on the abundance of species and eventually result in the extermination of such species from the area. If there is a human activity around the damping site the hooded vulture perch on the roof or stay on the ground near the beneficiaries, around the waste and just when the beneficiaries leave various birds aggregate on the feeding ground.

\section{Conclusion}

A total of 1,088 individual birds of six species belong to three families were recorded. The dominant family was Accipitridae, followed by Ardeidae and Carvidae. From the total six species only Thick-billed raven (Corvus crassirostris) was endemic to Ethiopia. Avian activity recorded throughout the study period were soaring, feeding, appeasement displays, watching alert posture, flying, roosting, body care and basking. The local vulture restaurant of the avifauna was intensively disturbed by human activities. Whenever there is human activity around the waste disposal site, birds kept on perching and resting on walls adjacent to their feeding site. Waste collectors and free ranging domestic dogs were the major threaten factors which interrupt the normal feeding activity of birds in the dumping site. Thus, conservation and management of species of global conservation significance should be done by designing separate vulture restaurant free of disturbance and chemical dumping.

\section{Way forward}

Based on the findings of the current study the following points are forwarded:-. The status of endemic birds visiting waste disposal sites should be studied so as to manage their decline from chemical contamination in the freely cast-off wastes. As well, the presence of aquatic birds in the dumping site may have an ecological implication on the deterioration of wetlands of Eastern eco-region. Thus, further ornithological survey should be conducted on specifics of avian ecology. Generally, the poor waste dumping mechanisms should be organized in vulture restaurant outside the city and support waste dependent birds of prey in the locality.

\section{Acknowledgements}

None.

\section{Conflict of interest}

The author declares no conflict of interest.

\section{References}

1. Wassie A, Teketay D, Powell N. Church forests in North Gondar Administrative Zone, northern Ethiopia. Forests, Trees and Livelihoods. 2005;15(4):349-374.

2. Ash J, Atkins JD. Birds of Ethiopia and Eritrea: An Atlas of Distribution. Journal of African Ornithology. 2009;80(2):125.
3. Tefera M. Wildlife in Ethiopia: endemic large mammals. World Journal of Zoology. 2011;6(2):108-116.

4. Yalden DW, Largen MJ, Kock D, et al. Catalogue of the mammals of Ethiopia and Eritrea. Revised Checklists, Zoogeography and conservation. Tropical Zoology. 1996;9(1):3-160.

5. Jacobs MJ, Schloeder CA. Impacts of Conflict on Biodiversity and Protected Areas in Ethiopia. USA: Mike Alwan; 2001. p 10-15.

6. USAID. Ethiopia Biodiversity and Tropical Forests 118/119 Assessment. Africa; 2008.

7. Lepage D. Avibase bird checklists of the world. The world bird database. 2006.

8. Şekercioğlu CH. Promoting community-based bird monitoring in the tropics: Conservation, research, environmental education, capacitybuilding, and local incomes. Biological Conservation. 2012;151(1):6973.

9. Carignan V, Villard MA. Effects of variations in micro-mammal abundance on artificial nest predation in conifer plantations and adjoining deciduous forests. Forest Ecology and Management. 2002;157(13):255-265.

10. Lim HC, Sodhi NS. Responses of avian guilds to urbanisation in a tropical city. Landscape and Urban Planning. 2004;66(4):199-215.

11. White JG, Antos MJ, Fitzsimons JA, et al. Non-uniform bird assemblages in urban environments: the influence of streetscape vegetation. Landscape and Urban Planning. 2005;71(2-4):20-24.

12. Arinaitwe J. Strategy for the Conservation and Sustainable Management of IBAs in Africa. Kenya: BirdLife Africa Partnership Secretariat; 2001.

13. Rodrigues ASL, Akçakaya HR, Andelman SJ, et al. Global gap analysis: priority regions for expanding the global protected-area network. Bio Science. 2004;54(12):1092-1100.

14. David H. Ethiopian conservation projects. UK: African conservation Foundation; 1996.

15. Dash C. Fundamentals of Ecology. 2nd ed. India: Tata McGraw-Hill publication; 1993.

16. Kress W. Birder's Hand book. USA: Dorling Kindersley Publishing; 2000.

17. Clergeau P, Mennecherz G, Salvage A, et al. Human perception and appreciation of bird: Motivation for wildlife conservation in urban environment of France. Avian ecology and Conservation in an urbanizing world. 2001:69-88.

18. Abduljawad M, Alem K, Abdu M, et al. Dire Dawa Administrativ Regional Conservation Strategy. Ethiopia: DDAEPA; 2001. p. 21-35.

19. Aynalem S, Bekele A. Species composition, relative abundance and distribution of bird fauna of riverine and wetland habitats of Infranz and Yiganda at southern tip of Lake Tana, Ethiopia. Tropical Ecology. 2008;49(2):199-209.

20. Bird life International. The BirdLife checklist of the birds of the world: Version 8. 2015.

21. Lee P, Rotenberry T. Relationship between bird's species and 3 species assemblage in forest habitat of Eastern North America. Journals of Biogeography. 2005;32:1139-1150.

22. Smith, R. Element of Ecology. 3rd ed. USA: Harper Collins Publishers Ltd; 1992.

23. Weidensau S. Raptors. England: Swaall Hill Press; 1996. p. 23-30. 